九州大学学術情報リポジトリ

Kyushu University Institutional Repository

\title{
The Application of Poly-dispersed Flow on Rectangular Airlift Photobioreactor Mixing Performance
}

\section{Hafidho I lham Muhammad}

Department of Mechanical Engineering, Faculty of Engineering, Universitas Indonesia

\section{Rahman, Arif}

Department of Mechanical Engineering, Faculty of Engineering, Universitas Indonesia

Nining Betawati Prihantini

Department of Biology, Faculty of Mathematics and Natural Sciences, Universitas Indonesia

\section{Deendarlianto}

Department of Mechanical and Industrial Engineering, Faculty of Engineering, Universitas Gadjah Mada

他

https://doi.org/10.5109/4150508

出版情報：Evergreen. 7 (4)，pp.571-579，2020-12. 九州大学グリーンテクノロジー研究教育センター バージョン：

権利関係 : 


\title{
The Application of Poly-dispersed Flow on Rectangular Airlift Photobioreactor Mixing Performance
}

\author{
Hafidho Ilham Muhammad ${ }^{1}$, Arif Rahman ${ }^{1}$, Nining Betawati Prihantini², \\ Deendarlianto $^{3}$, Nasruddin ${ }^{1, *}$ \\ ${ }^{1}$ Department of Mechanical Engineering, Faculty of Engineering, Universitas Indonesia, \\ Depok, 16424, Indonesia \\ ${ }^{2}$ Department of Biology, Faculty of Mathematics and Natural Sciences, Universitas Indonesia, \\ Depok, 16424, Indonesia \\ ${ }^{3}$ Department of Mechanical and Industrial Engineering, Faculty of Engineering, Universitas Gadjah Mada, \\ Yogyakarta, 55281, Indonesia
}

\section{*Corresponding Author’s email: Nasruddin@eng.ui.ac.id}

(Received November 4, 2020; Revised December 10, 2020; accepted December 16, 2020).

\begin{abstract}
The use of the photobioreactor is intended to monitor certain parameters affecting the growth of microalgae and to reduce the potential for contamination. The best microalgae growth is expected to be achieved through the optimal photobioreactor design. This research is proposed by implementing a poly-dispersed bubble flow for two different rectangular airlift photobioreactor in order to gain insights into the optimum configuration such that mixing and good microalgae growth can be achieved. ANSYS Fluent is used to solve the model of CFD. The simulations were carried out for two operating conditions, 1 and 2.5 LPM (liter per minute) gas flow rates. The utilization of poly-dispersed bubbly flow can reduce the discrepancy with regard to the experimental data. Better simulation results in terms of microalgae growth were shown by photobioreactor with horizontal baffles than photobioreactor without baffles in higher gas flow rates in the form of mixing performance.
\end{abstract}

Keywords: Computational Fluid Dynamics; Photobioreactor; Microalgae; Renewable Energy

\section{Background}

Increasing demand for energy occurs in a country as its economics is expected to grow during the time ${ }^{1)}$. This rapid change of many developing market economies has been adversely affecting the quality of life and raising concerns about environmental damages, for example climate change ${ }^{2)}$. Power generation or chemical products from fossil fuel transition to the non-conventional energy sources like biomass would bring advantage to $\mathrm{CO}_{2}$ mitigation by absorbing it from the atmosphere during the planting ${ }^{3}$.

The diversification of energy sources, clean energy and energy saving technology are important key factors for energy security ${ }^{4)}$. The non-conventional and renewable energy sources like wind energy, ocean energy, geothermal energy, photovoltaic energy, waste and biomass energy have to be explored to maintain overall developments and reduce energy dependence on others ${ }^{11}$. Biomass growth of microalgae can be used potentially as biofuel feedstock with suitable photobioreactor and growth media ${ }^{5}$. The use of microalgae as one of renewable energy sources is very promising but the way how to use microalgae's potential efficiently and develop appropriate technology still become the biggest challenge ${ }^{6)}$

The existence of microalgae has benefited many aspects of life and crucial for the earth ecosystem. Used for the source for food and the pharmaceutical industries, microalgae has long been known for its potential ${ }^{7)}$. The benefits of microalgae such as absorbing $\mathrm{CO}_{2}$, producing alternative energy and being used as an absorbent for wastewater, have a significant role in the environment.

The microalgae cultivation can be done in open systems such as open-ponds or closed systems named photobioreactor $^{8}$. Both systems require the intensity of light as a critical factor affecting the growth ${ }^{9}$. The type of microalgae cultivation such as open-ponds, bubble column, flat plate and tubular photobiorector has its own advantages and disadvantages ${ }^{10)}$. The open systems need less cost to be fabricated and operated and have better production capacity. However, the open systems require more land area and prone to contamination as well as selfshadowing which can cause microalgae death ${ }^{11)}$. Photobioreactor has advantages such as better control of culture and growth conditions. The excessive 
mechanically stirred flow within photobioreactor makes turbulence which can affect the growth and production of microalgae by damaging the cellular structure ${ }^{11,12)}$. On the other side, a poor stirred flow can increase the sedimentation and the death of cell ${ }^{11,12}$.

In an ideal photobioreactor geometry, mixing parameters force microalgae to be distributed evenly within photobioreactor. Mixing parameters lead microalgae to undergo light and dark cycle short enough, keep microalgae in suspension, remove thermal stratification and facilitate the distribution of nutrient as well as increase gas-liquid mass transfer ${ }^{10)}$. The geometry of the photobioreactor and its operating conditions must have good criteria in order to promote microalgae growth so that the high result of biomass can be obtained ${ }^{13)}$. Optimization of photobioreactor design in terms of mixing parameters can be done by modifying the geometry of photobioreactor ${ }^{14)}$. Static baffles or motionless baffles in the photobioreactor enhance the mixing and gas-liquid mass transfer ${ }^{15)}$.

Most of the researches on gas-liquid flow simulation have been done with two computational fluid dynamics (CFD) simulation approaches. The two approaches are the Euler-Lagrange approach and the Euler-Euler approach. The advantages of Euler-Lagrange approach are on detail and complete physical characteristics because this approach tracks the individual bubbles in the photobioreactor by solving an equation for Newton's second law while accounting for the forces exerted on bubbles. The high computational cost becomes the disadvantage of the Euler-Lagrange approach. On the other side, the Euler-Euler approach gives reasonable predictions while maintaining the computer memory and computational time affordable.

Computational fluid dynamics (CFD) helps better understand the underlying fluid dynamics within the photobioreactor. The eulerian two-phase flow approach is widely utilized to model the dispersed multiphase flows that happen within photobioreactor ${ }^{16,17)}$. The interactions between the dispersed phase and the liquid phase are modeled by closure models. A reliable set of closure models is needed to predict the unknown setups by the use of extensive model validation ${ }^{18)}$. Bubble size distribution is important particularly because all the closure models depend on the bubble size ${ }^{19}$.

The combination between the population balance model (PBM) and CFD framework beneficial in the way describing the bubble size distribution and gas holdup by taking bubble breakup and coalescence into account. On the interphase interaction, the population balance model enables it to predict the local gas-liquid interfacial area and the flow behaviour in diverse flow regimes ${ }^{20)}$.

In this research, photobioreactor with horizontal baffles and without baffles were compared to investigate the mixing performance. The poly-dispersed flow of gas phase is introduced for both photobioreactors to get more realistic results. The turbulence kinetic energy and turbulence eddy dissipation are compared as the results of hydrodynamic characteristics and mixing parameters using a two-dimensional CFD flow simulation.

\section{Methodology}

\subsection{Simulation}

The conservation equation of mass and momentum are solved for each phase can be seen as:

$$
\begin{aligned}
& \frac{\partial\left(\alpha_{q} \rho_{q}\right)}{\partial t}+\nabla \cdot\left(\alpha_{q} \rho_{q} u_{q}\right)=0 \\
& \frac{\partial\left(u_{q} \alpha_{q} \rho_{q}\right)}{\partial t}+\nabla \cdot\left(\alpha_{q} \rho_{q} u_{q} u_{q}-\mu_{q} \alpha_{q}\left(\nabla u_{q}+\left(\nabla u_{q}\right)^{T}\right)\right) \\
& =-\alpha_{q} \cdot \nabla P+F_{p q}+\alpha_{q} \rho_{q} g
\end{aligned}
$$

The volume based bubble number density function which using class method solved PBM numerically is defined as follows:

$$
\begin{aligned}
& \frac{\partial}{\partial t} n_{i}+\nabla \cdot\left(u_{i} n_{i}\right)=\sum_{d_{j}=d_{i}}^{d_{\max }} \Omega_{B}\left(d_{j}: d_{i}\right)-\Omega_{B}\left(d_{i}\right) \\
& +\sum_{d_{j}=d_{\min }}^{\frac{d_{i}}{2}} \Omega_{C}\left(d_{j}: d_{i}-d_{j}\right)-\sum_{d_{j}=d_{\min }}^{d_{\max }-d_{i}} \Omega_{C}\left(d_{j}: d_{i}\right)
\end{aligned}
$$

The gas volume fraction can be defined as follows:

$$
\alpha_{g}=\sum_{i=1}^{N} n_{i} \frac{\pi}{6} d_{i}^{3}
$$

The collision frequency and coalescence efficiency Luo coalescence kernel given as follows ${ }^{21)}$ :

$$
\begin{aligned}
& \Omega_{C}\left(d_{i}: d_{j}\right) \\
& =c_{0}\left(d_{i}+d_{j}\right)^{2}\left(d_{i}^{2 / 3}+d_{j}^{2 / 3}\right)^{1 / 2} \varepsilon^{1 / 3} n_{i} n_{j} \exp \left\{-\frac{t_{c}}{t_{I}}\right\}
\end{aligned}
$$

The breakup rate and daughter size distribution predicted by Luo breakup kernel directly from the models then the total breakup rate is given as:

$$
\Omega_{B}\left(d_{i}\right)=\int_{0}^{0.5} \Omega_{B}\left(d_{i}: d_{j}\right) d_{f}
$$

The binary bubble breakup refers to Luo and Svendsen in 1996 can be defined $\mathrm{as}^{22)}$ : 


$$
\begin{aligned}
& \Omega_{B}\left(d_{i}: d_{j}\right) \\
& =0.9238 \varepsilon^{1 / 3} d_{i}^{-2 / 3} \alpha \int_{\xi \min }^{1} \frac{(1+\xi)^{2}}{\xi^{11 / 3}} \exp \left(\frac{12 \sigma c_{f}}{\rho_{q} \varepsilon^{2 / 3} d_{i}^{5 / 3}} \xi^{-11 / 3}\right) d \xi
\end{aligned}
$$

A transient two dimensional (2D) simulation in a rectangular photobioreactor is chosen due to the enormous amount of computational time for three-dimensional simulation (3D). The simulation involved two-phase flow which consist of air as the dispersed phase and water as the continuous phase. The superficial gas velocity was calculated from the volumetric flow rate of air that passes through porous sparger located at the lower part of the photobioreactor near the base. The volumetric gas flow rate was varied between 1 and 2.5 LPM (liter per minute). The length and height of rectangular airlift photobioreactor were $0.4 \mathrm{~m}$ both. The height of the liquid was set to $0.33 \mathrm{~m}$ which corresponds to the volume of 20 L. The inlet geometry of the photobioreactor consisted of two porous spargers that are connected with the hub so that the bubbles can be distributed widely. Bubbles are assumed to be uniformly distributed from the surface of porous sparger due to the limitation of the mesh size and computational cost to model the exact size and amount of pores. The research done by Buwa and Ranade on the investigation of the influence of the sparging design which using a perforated plate and the sintered plate supports this assumption, the research shows that there is no significant difference between them ${ }^{23)}$. The outlet and wall were set to atmospheric pressure and no-slip boundary conditions, respectively.

Each phase utilizes the eulerian reference. Constant density is considered to model the phenomenon. Realizable mixture $\mathrm{k}-\varepsilon$ is occupied for turbulence model. The time-dependent simulation or transient is carried out with a time of $30 \mathrm{~s}$ to reach a steady-state then $0.01 \mathrm{~s}$ is chosen as simulation time step. At first, time step size has to be ensured according to courant number.

Two different rectangular airlift photobioreactor geometries were carried out as shown in Figure 1. The external dimensions namely, $400 \mathrm{~mm}$ in length, $150 \mathrm{~mm}$ in width, and $400 \mathrm{~mm}$ in height were designated for both geometries. Baffles are installed horizontally with a width of $25 \mathrm{~mm}$. The photobioreactor with baffles and without baffles were simulated under gas flow rates of 1 LPM and 2.5 LPM. The spatial discretization was set to the firstorder upwind scheme for the equations. The computational domain of 8069 cells and 8089 cells was set for photobioreactor with baffles and without baffles respectively. The PBM model was adopted to calculate the bubble size distribution while the bubble distributed from porous sparger. 9 - 15 bubble classes were sufficient for bubble size distribution for low superficial gas velocity ${ }^{24)}$. The details of bubble classes are presented in table 1 and table 2. The breakage kernel and aggregation kernel adopted for this simulation are Luo and Luo respectively for breakup and coalescence of bubbles phenomena.
Convergence criteria for all parameters were set for thirdorder $\left(10^{-3}\right)$ magnitude of residual drop. After the first five seconds of simulation, the data sampling turned on to obtain time-averaged values.
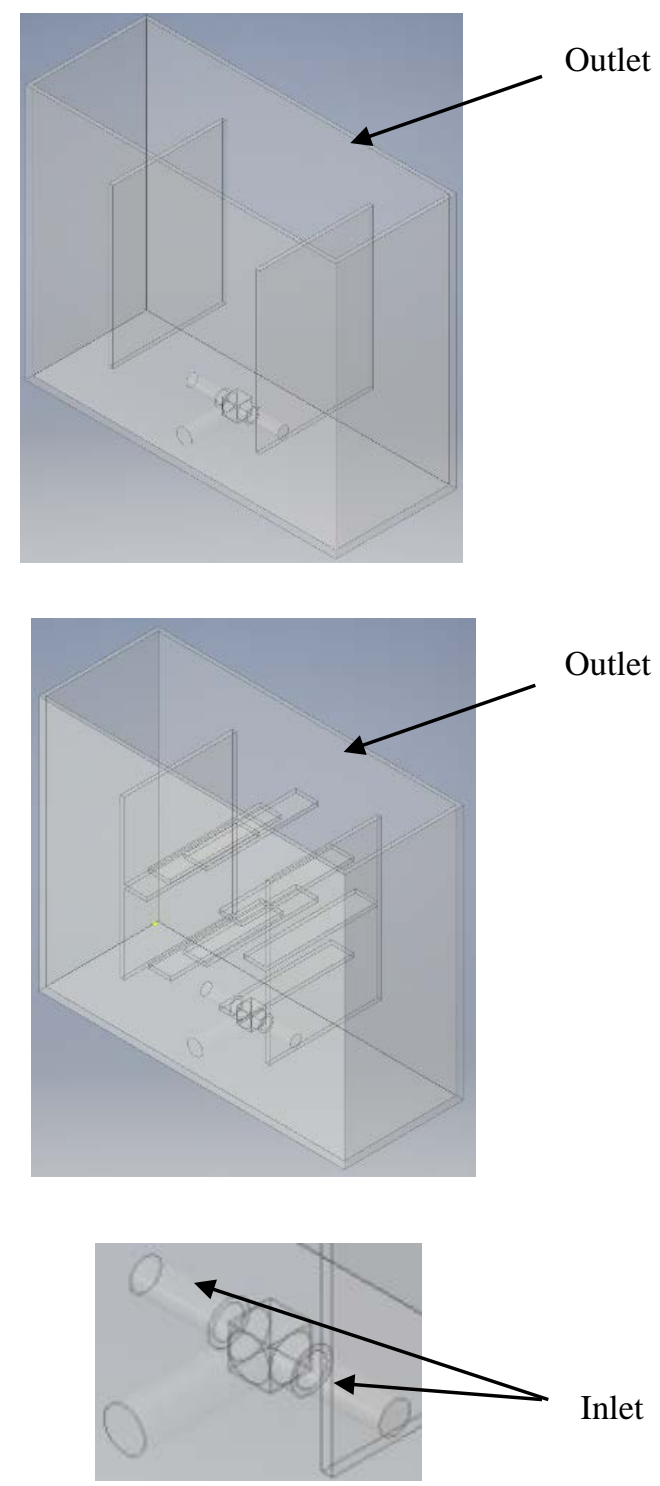

Fig 1: Photobioreactor without baffles and with baffles 
Table 1. Bubble classes of 1 LPM operating condition

\begin{tabular}{|c|c|}
\hline Classes & Sizes $(\boldsymbol{\mu m})$ \\
\hline 1 & 1677 \\
\hline 2 & 1283 \\
\hline 3 & 981 \\
\hline 4 & 750 \\
\hline 5 & 574 \\
\hline 6 & 439 \\
\hline 7 & 335 \\
\hline 8 & 256 \\
\hline 9 & 196 \\
\hline 10 & 150 \\
\hline 11 & 115 \\
\hline
\end{tabular}

Table 2. Bubble classes of 2.5 LPM operating condition

\begin{tabular}{|c|c|}
\hline Classes & Sizes $(\boldsymbol{\mu m})$ \\
\hline 1 & 2316 \\
\hline 2 & 1805 \\
\hline 3 & 1406 \\
\hline 4 & 1095 \\
\hline 5 & 853 \\
\hline 6 & 665 \\
\hline 7 & 518 \\
\hline 8 & 403 \\
\hline 9 & 314 \\
\hline 10 & 245 \\
\hline 11 & 191 \\
\hline 12 & 148 \\
\hline 13 & 116 \\
\hline
\end{tabular}

There are some assumptions underlying this research in terms of hydrodynamic simulation. First, there is no absorption between each phase. Second, during the simulation, the domain temperature is kept uniform so that there is no heat loss. Third, there is no gas initially and the water completely filled the photobioreactor.

\subsection{Experiment}

Some photos and videos were taken with SONY RX 100 camera at a resolution of 1920 x 1080 pixels for various gas flow rates. These photos and videos were analyzed and processed with image processing software to obtain mean bubble sizes and bubble velocity. The bubble image processing was done to measure the bubble size through an open source software "imageJ", while the video was broken down into some pieces of photo as binary format and then the bubble velocity is obtained using "PIVlab", an image-based motion detection software ${ }^{25)}$. The mean bubble sizes will be implemented to simulation in the form of poly-dispersed bubble inlet and bubble velocity will be used as experimental data.

\section{Result and Analysis}

\subsection{Model Validation}

Initially, the result from poly-dispersed bubble flow simulation compared to mono-dispersed bubble flow simulation with regard to experimental data as shown in table 3. It is presented that the discrepancy of all simulations are in a reasonable value. The poly-dispersed simulation in photobioreactor without baffles leads to a better result. Otherwise, the mono-dispersed simulation in photobioreactor with baffles shows a better result. All of the data compared are carried out in 1 LPM operating condition.

Table 3. Comparison to experimental data

\begin{tabular}{|c|c|c|c|c|c|}
\hline \multirow[t]{2}{*}{ PBR } & \multirow[t]{2}{*}{$\begin{array}{c}\text { Bubble } \\
\text { Type }\end{array}$} & \multirow[t]{2}{*}{ Point } & \multicolumn{2}{|c|}{$\begin{array}{c}\text { Averaged } \\
\text { Bubbles Velocity } \\
(\mathrm{m} / \mathrm{s})\end{array}$} & \multirow[t]{2}{*}{$\begin{array}{c}\text { Error } \\
(\%)\end{array}$} \\
\hline & & & CFD & PIVlab & \\
\hline \multirow{2}{*}{$\begin{array}{l}\text { Non- } \\
\text { Baffles }\end{array}$} & $\begin{array}{c}\text { Mono- } \\
\text { dispersed }\end{array}$ & \multirow{2}{*}{$\begin{array}{l}1 / 2 \text { of } \\
\text { Height }\end{array}$} & 0.347 & \multirow{2}{*}{0.327} & 6.068 \\
\hline & $\begin{array}{c}\text { Poly- } \\
\text { dispersed }\end{array}$ & & 0.339 & & 3.680 \\
\hline \multirow{2}{*}{ Baffles } & $\begin{array}{c}\text { Mono- } \\
\text { dispersed }\end{array}$ & \multirow{2}{*}{$\begin{array}{l}1 / 2 \text { of } \\
\text { Height }\end{array}$} & 0.249 & \multirow{2}{*}{0.232} & 7.254 \\
\hline & $\begin{array}{c}\text { Poly- } \\
\text { dispersed }\end{array}$ & & 0.257 & & 10.743 \\
\hline
\end{tabular}

Luo-Luo models predict lower gas holdup compared to experimental data ${ }^{26)}$. Lower gas holdup is caused due to the size of the bubble increases. The result from polydispersed bubbly flow simulation in photobioreactor with baffles shows higher velocity because of the bubble size increases.

\subsection{Result and Discussion}

The turbulence kinetic energy and turbulence eddy dissipation for both photobioreactors and both operating conditions are shown in table 4 as mixing parameters. Turbulence kinetic energy in water represents the turbulent intensity in the photobioreactor. High value of turbulence kinetic energy indicates superior fluid mixing ${ }^{27)}$. Superior fluid mixing plays dominant role in preventing microalgae sedimentation and thermal stratification as well as enhancing uniform distribution of nutrients and shorter light and dark cycle. Turbulence eddy dissipation is important aspect for mass transfer because it involves mixing at dominant molecular transport processes ${ }^{28}$. This type of mixing influences the effectivity of mass transfer between gas phase to microalgae. The results exhibit that better operating condition leads to better mixing parameters. The photobioreactor with baffles has higher value of mixing parameters in higher operating condition while in lower operating condition has lower value. 
Table 4. Mixing performance in photobioreactors

\begin{tabular}{|c|c|c|c|}
\hline \multirow{2}{*}{ PBR } & $\begin{array}{c}\text { Gas Flow } \\
\text { Rates (LPM) }\end{array}$ & $\begin{array}{c}\text { Averaged } \\
\text { TKE }\left(\mathrm{m}^{-2} \mathrm{~s}^{-2}\right)\end{array}$ & $\begin{array}{c}\text { Averaged } \\
\text { TED }\left(\mathrm{m}^{-2} \mathrm{~s}^{-3}\right)\end{array}$ \\
\hline \multirow{2}{*}{$\begin{array}{c}\text { Non- } \\
\text { Baffles }\end{array}$} & 1 & $203 \times 10^{-5}$ & $298 \times 10^{-5}$ \\
\cline { 2 - 4 } & 2.5 & $171 \times 10^{-5}$ & $380 \times 10^{-5}$ \\
\hline \multirow{2}{*}{ Baffles } & 1 & $91.8 \times 10^{5}$ & $259 \times 10^{-5}$ \\
\cline { 2 - 4 } & 2.5 & $206 \times 10^{-5}$ & $858 \times 10^{-5}$ \\
\hline
\end{tabular}

A closer observation of mixing performance previously shown in table 4 and presented in figure 2 to figure 5 highlights a unique phenomenon in the operating condition of 1 LPM. The turbulence kinetic energy and turbulence eddy dissipation of photobioreactor with baffles are lower compared to the one without baffles in this operating condition. There are many possible reasons to this phenomenon but the most possible one is due to the tendency of bubble coalescence and accumulated under the baffle in lower operating condition giving the local and overall circulation over the photobioreactor lower. The bubbles accumulated under the baffles indicate that gas holdup within the photobioreactor is lower and form a bigger size of bubbles resulting in low mass transfer from gas phase to microalgae. The lower gas holdup may also be caused by the employed model, Luo-Luo models that under predicted the gas holdup compared to the experimental $\operatorname{data}^{28}$. The feasible way to overcome this occurrence is to increase the operating condition which means increasing the gas supply.

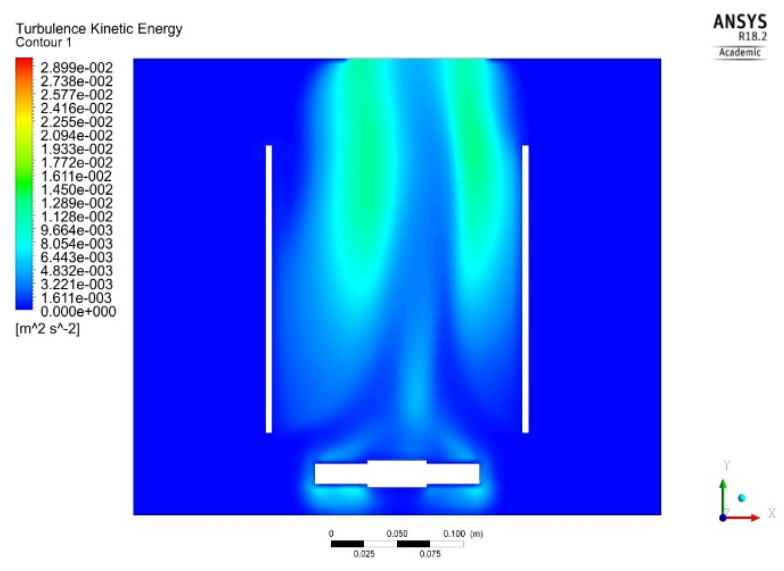

Fig 2: Turbulence kinetic energy for photobioreactor without baffles at 1 LPM

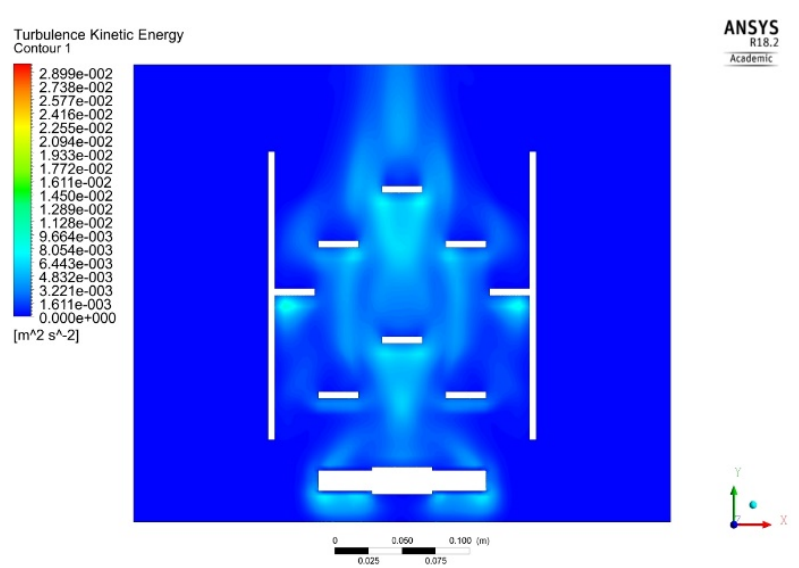

Fig 3: Turbulence kinetic energy for photobioreactor with baffles at $1 \mathrm{LPM}$

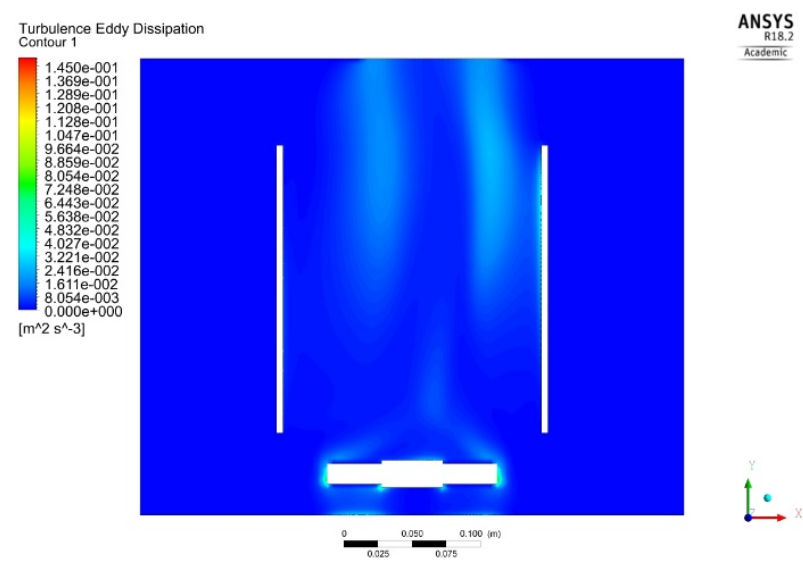

Fig 4: Turbulence eddy dissipation for photobioreactor without baffles at $1 \mathrm{LPM}$

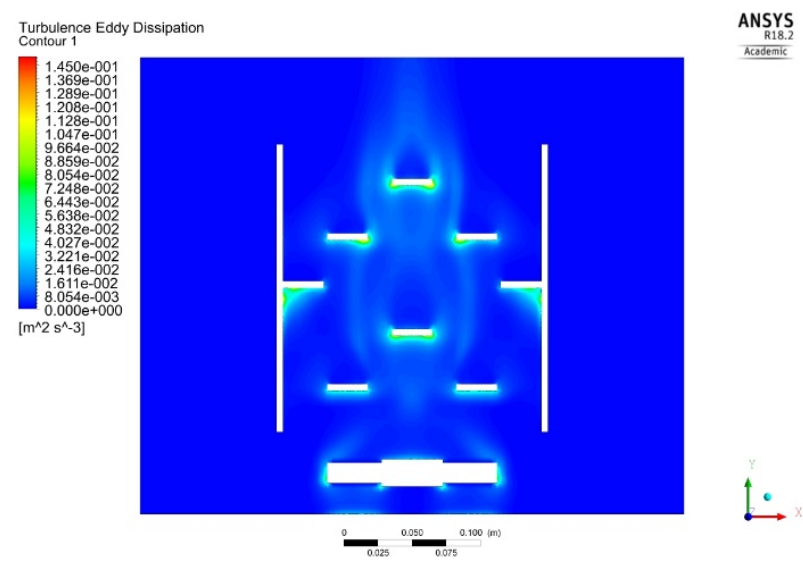

Fig 5: Turbulence eddy dissipation for photobioreactor with baffles at $1 \mathrm{LPM}$

The bubble distribution within photobioreactor in the form of number density are shown in figure $6-9$. For all of the simulations, the bubble distribution trend has the highest value of number density with the size of bubble same as the initial size at the inlet. Figure 6 and figure 8 present the bubble size distribution for photobioreactor with baffles at different gas flow rates. The higher gas 
flow rates result to the higher number density of the bubbles. Figure 6 and figure 7 show the bubble size distribution for different type of photobioreactor. It can be seen in photobioreactor with baffles, the number density for bubble diameter of $750 \mu \mathrm{m}$ is lower and $1677 \mu \mathrm{m}$ is higher compared to photobioreactor without baffles. The possible reason is that the photobioreactor with baffles tends to accumulate bubbles under the baffles. It is expected for photobioreactor with baffles to accumulate some bubbles under its baffles to increase bubble time residence and increase mass transfer. The accumulated bubbles for some times will cause bubble coalescence.

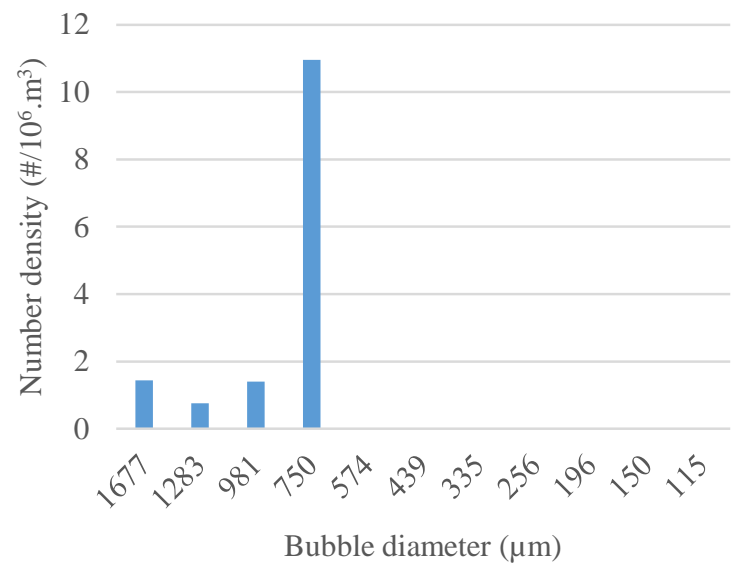

Fig 6: Bubble size distribution for photobioreactor without baffles at 1 LPM

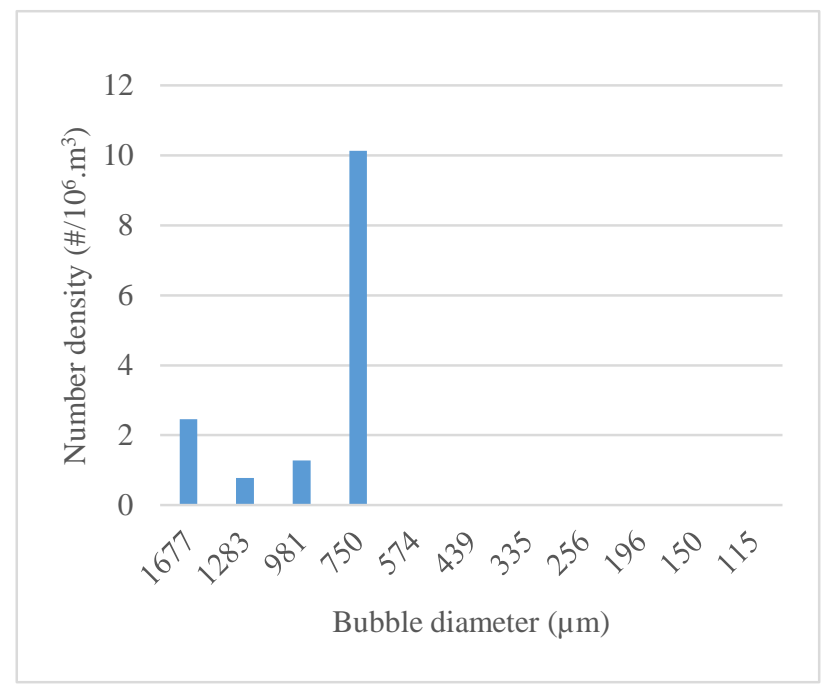

Fig 7: Bubble size distribution for photobioreactor with baffles at 1 LPM

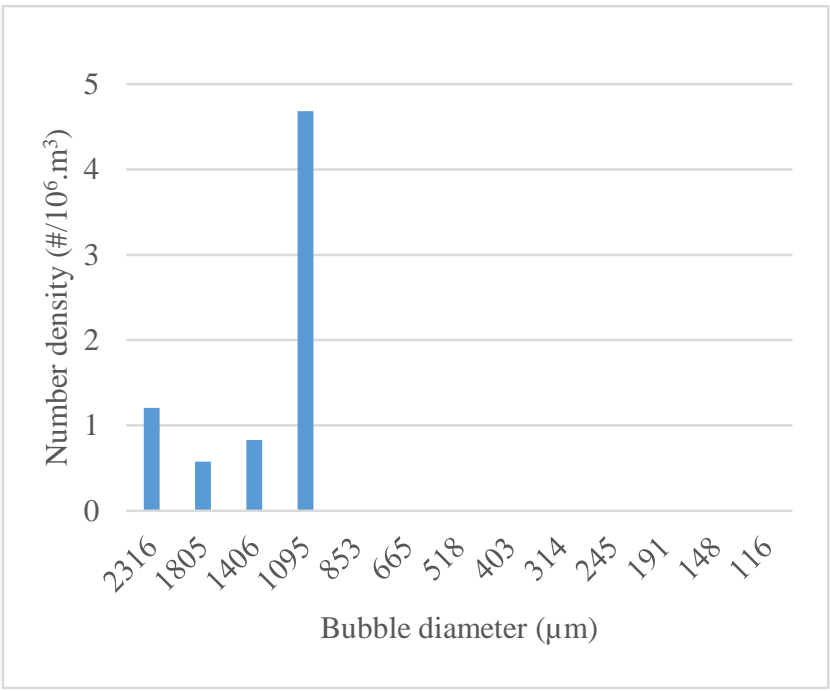

Fig 8: Bubble size distribution for photobioreactor without baffles at 2.5 LPM

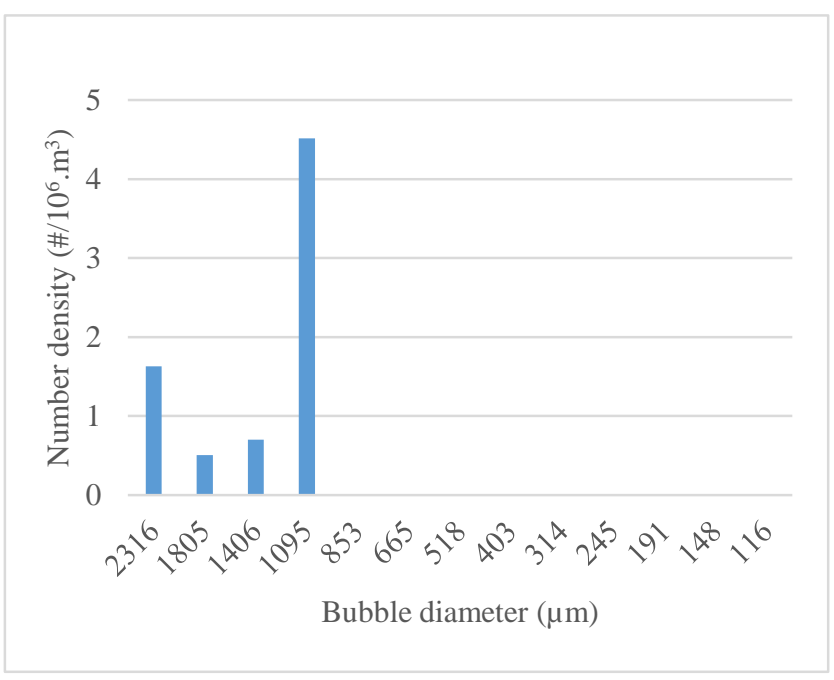

Fig 9: Bubble size distribution for photobioreactor with baffles at 2.5 LPM

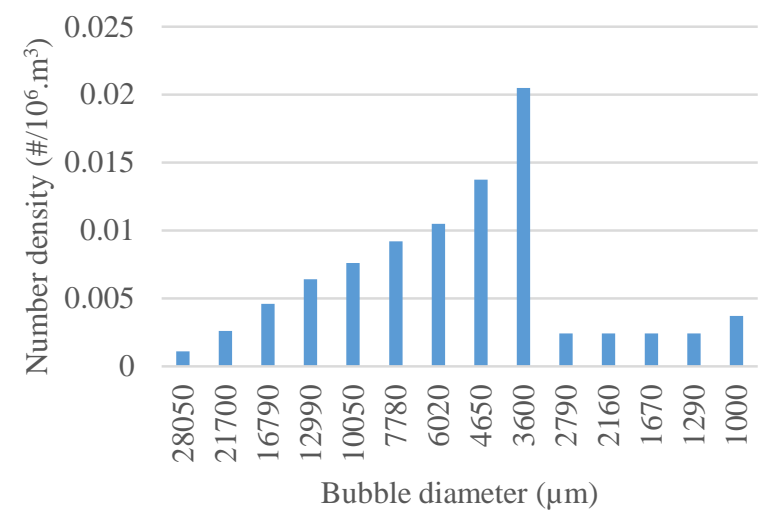

Fig 10: Bubble size distribution with Luo's breakup and Luo's coalescence model ${ }^{26)}$ 
There are several differences in photobioreactor considering the installation of the baffles in terms of the flow mixing. The photobioreactor without baffles produces trailing vortex which the radial flow of bubbles causes the gas accumulation in the center area, while in the surrounding areas the flow moves downward. The photobieareactor with baffles has other type of flow as the baffles disturb the vortex. The installation of baffles in the dead zone of flow generates a directional flow, causing the uniform distribution of bubbles that lifting the microalgae to flow upward to the surface of the liquid ${ }^{29}$ )

The contour of liquid velocity for all simulations are presented in figure $11-14$. The results show more intense of velocity distribution as the simulation goes with higher operating condition.
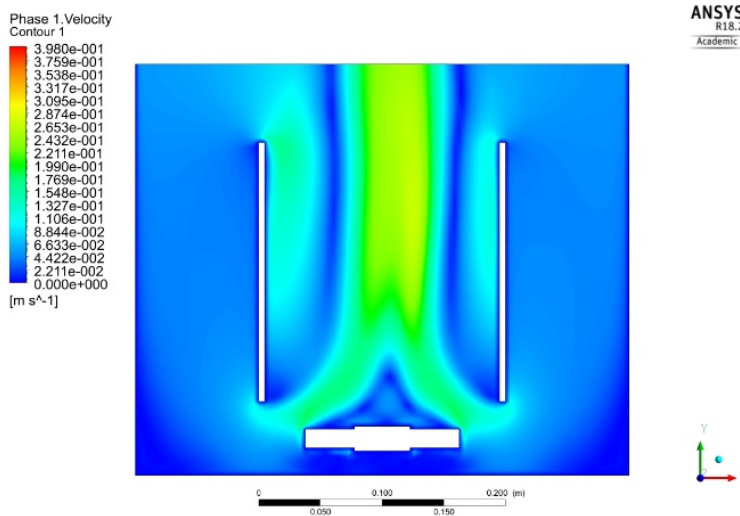

Fig 11: Liquid velocity contour for photobioreactor without baffles at 1 LPM

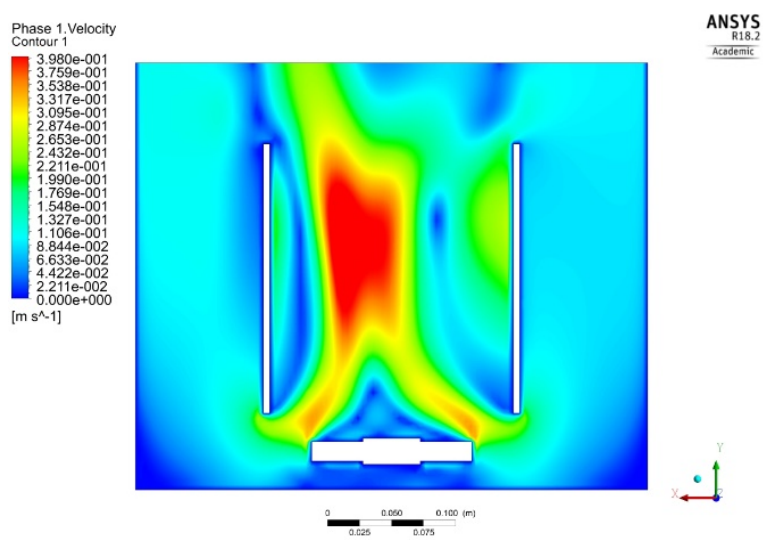

Fig 12: Liquid velocity contour for photobioreactor without baffles at 2.5 LPM

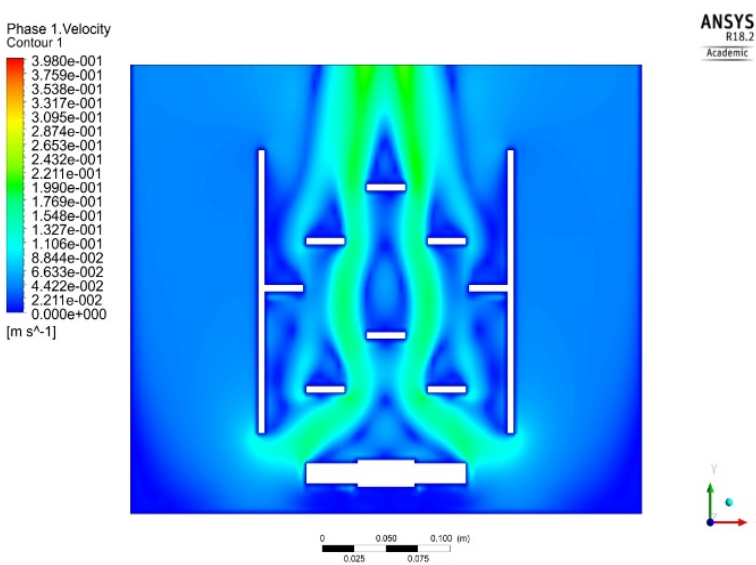

Fig 13: Liquid velocity contour for photobioreactor with baffles at $1 \mathrm{LPM}$

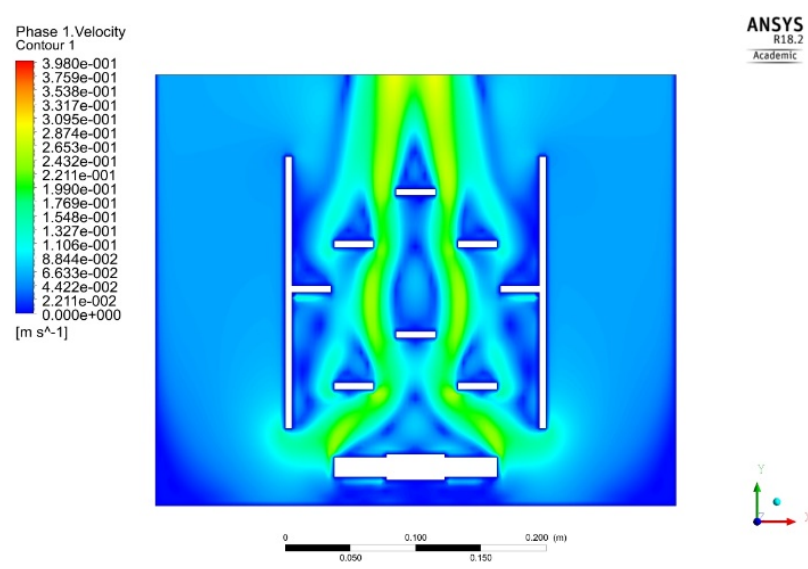

Fig 14: Liquid velocity contour for photobioreactor with baffles at 2.5 LPM

For all simulations, it is also shown that a higher value of velocity is concentrated at the center of photobioreactor. This phenomenon can be caused by the larger bubble that enters the photobioreactor. Larger bubble tends to keep away from the wall and the larger size of the bubble means it has higher rising velocity.

\section{Conclusion}

Poly-dispersed bubble flow simulations have been carried out for 1 LPM and 2.5 LPM. The simulations first compared to the experimental data and show an acceptable value of error. Mixing parameters are determined from the simulations. Photobioreactor with baffles has better mixing parameters in the operating condition of 2.5 LPM while the photobioreactor without baffles has lower mixing parameters in the operating condition of 2.5 LPM. The higher the operating condition used, in this case is gas flow rates, the better mixing performance in both photobioreactors. The application of poly-dispersed flow not always give better prediction considering the model used is two dimensional (2D) simulation, but this application can lead to more realistic flow characteristics. In the future, the three dimensional 
(3D) simulation is expected to give better prediction because it can take into account one degree of freedom that does not exist in two-dimensional simulations.

\section{Acknowledgements}

The author would like to express gratitude for Directorate of Research and Community Engagements Universitas Indonesia (DRPM UI) for funding this research through PIT 92019 scheme with contract number NKB-0069/UN2.R3.1/HKP.05.00/2019.

\section{References}

1) M. Kumar, "Energy security and sustainability in japan,” 2 (1) 49-56 (2015).

2) R. Narayan, "Green disclosure practices in india : a study of select companies,” 2 (2) 5-13 (2015).

3) N. Ayu, "Reduction of co _ 2 emission by integrated biomass gasification-solid oxide fuel cell combined with heat recovery and in-situ co _ 2 utilization reduction of co 2 emission by integrated biomass gasific ation-solid oxide fuel cell combined with heat recovery,” 6 (3) 254-261 (2019).

4) H. Gima, and T. Yoshitake, "Kyushu university institutional repository a comparative study of energy security in okinawa prefecture and the state of hawaii a comparative study of energy security in okinawa prefecture and the state of hawaii," 3 (2) 36-44 (2016).

5) S. Rafii, A. Muhammad, S.R. Ardiansyah, A.M. Orlando, A. Rahman, and N.B. Prihantini, "Tubular photobioreactor: a preliminary experiment using synechococcus sp . ( cyanobacteria ) cultivated in npk media for biomass production as biofuel feedstock tubular photobioreactor: a preliminary experiment using synechococcus sp . ( cyanobacteria ) cultivated in npk media for biomass production as biofuel feedstock," 6 (2) 157-161 (2019).

6) A. Rahman, and N.B. Prihantini, "Fatty acid of microalgae as a potential feedstock for biodiesel production in indonesia fatty acid of microalgae as a potential feedstock for biodiesel production in indonesia,” $020059 \quad$ (January) (2019). doi:10.1063/1.5086606.

7) S.R. Chae, E.J. Hwang, and H.S. Shin, "Single cell protein production of euglena gracilis and carbon dioxide fixation in an innovative photo-bioreactor," Bioresour. Technol., 97 (2) 322-329 (2006). doi:10.1016/j.biortech.2005.02.037.

8) A.N. García, N. García, A.R. Marin, R. Marin, Y.C. Lopez, C. Lopez, J. Carmen, and Z. Loria, "Effect of hydrodynamic conditions of hotobioreactors on lipids productivity in microalgae photobioreactors," (n.d.). doi:10.5772/intechopen.74134.

9) A. Martins, N.S. Caetano, and T.M. Mata, "Microalgae for biodiesel production and other applications : a review,” 14 217-232 (2010). doi:10.1016/j.rser.2009.07.020.

10) C.U. Ugwu, H. Aoyagi, and H. Uchiyama, "Photobioreactors for mass cultivation of algae," Bioresour. Technol., 99 (10) 4021-4028 (2008). doi:10.1016/j.biortech.2007.01.046.

11) J.U. Grobbelaar, "Microalgal biomass production : challenges and realities," 135-144 (2010). doi:10.1007/s11120-010-9573-5.

12) S. Powtongsook, P. Pavasant, and T. Roong, "Comparison between airlift photobioreactor and bubble column for skeletonema costatum cultivation," (October) (2011). doi:10.4186/ej.2011.15.4.53.

13) J.P. Bitog, I.B. Lee, C.G. Lee, K.S. Kim, H.S. Hwang, S.W. Hong, I.H. Seo, K.S. Kwon, and E. Mostafa, "Application of computational fluid dynamics for modeling and designing photobioreactors for microalgae production: a review," Comput. Electron. Agric., $76 \quad$ (2) 131-147 (2011). doi:10.1016/j.compag.2011.01.015.

14) H.I. Muhammad, A. Rahman, and N.B. Prihantini, "Comparison of two microalgae rectangular airlift photobioreactors using computational fluid dynamics ( cfd ) comparison of two microalgae rectangular airlift photobioreactors using computational fluid dynamics,” 030052 (September) (2020).

15) C.U. Ugwu, J.C. Ogbonna, and H. Tanaka, "Improvement of mass transfer characteristics and productivities of inclined tubular photobioreactors by installation of internal static mixers," Appl. Microbiol. Biotechnol., $58 \quad$ (5) 600-607 (2002). doi:10.1007/s00253-002-0940-9.

16) H.P. Luo, and M.H. Al-Dahhan, "Verification and validation of cfd simulations for local flow dynamics in a draft tube airlift bioreactor,” Chem. Eng. Sci., 66 (5) 907-923 (2011). doi:10.1016/j.ces.2010.11.038.

17) T. Ziegenhein, R. Rzehak, and D. Lucas, "Transient simulation for large scale fl ow in bubble columns," Chem. Eng. Sci., 122 1-13 (2015). doi:10.1016/j.ces.2014.09.022.

18) D. Lucas, R. Rzehak, E. Krepper, T. Ziegenhein, Y. Liao, S. Kriebitzsch, and P. Apanasevich, "Reactor safety,” Nucl. Eng. Des., (2015). doi:10.1016/j.nucengdes.2015.07.007.

19) T. Ziegenhein, J. Zalucky, R. Rzehak, and D. Lucas, "On the hydrodynamics of airlift reactors, part i : experiments on the hydrodynamics of airlift reactors , part i : experiments,” Chem. Eng. Sci., 150 (March 2017) 54-65 (2016). doi:10.1016/j.ces.2016.04.039.

20) C. Xing, T. Wang, and J. Wang, "Experimental study and numerical simulation with a coupled cfd - pbm model of the effect of liquid viscosity in a bubble column,” Chem. Eng. Sci., 95 313-322 (2013). doi:10.1016/j.ces.2013.03.022.

21) H. Jupsin, E. Praet, and J.L. Vasel, "Dynamic mathematical model of high rate algal ponds (hrap)," Water Sci. Technol., 48 (2) 197-204 (2003). 
22) H. Luo, and H.F. Svendsen, "Theoretical model for drop and bubble breakup in turbulent dispersions," 42 (5) 1225-1233 (1996).

23) V. V Buwa, and V. V Ranade, "Dynamics of gas liquid ow in a rectangular bubble column: experiments and single $=$ multi-group $\mathrm{cfd}$ simulations," 57 4715-4736 (2002).

24) R. Bannari, F. Kerdouss, B. Selma, A. Bannari, and P. Proulx, "Three-dimensional mathematical modeling of dispersed two-phase flow using class method of population balance in bubble columns," 32 32243237

(2008). doi:10.1016/j.compchemeng.2008.05.016.

25) J.D. Putra, A. Rahman, and N.B. Prihantini, "The effect of modification photobioreactor bubble columns by using horizontal baffle on bubble velocity for microalgae the effect of modification photobioreactor bubble columns by using horizontal baffle on bubble velocity for microalgae," 030053 (September) 3-9 (2020).

26) A.H. Syed, M. Boulet, T. Melchiori, and J. Lavoie, "CFD simulations of an air-water bubble column: effect of luo coalescence parameter and breakup kernels," $5 \quad$ (September) (2017). doi:10.3389/fchem.2017.00068.

27) L. Xu, R. Liu, F. Wang, and C.Z. Liu, "Development of a draft-tube airlift bioreactor for botryococcus braunii with an optimized inner structure using computational fluid dynamics," Bioresour. Technol., 119 300-305 (2012). doi:10.1016/j.biortech.2012.05.123.

28) B. Kumar, "Energy dissipation and shear rate with geometry of baffled surface aerator," Chem. Eng. Res. $\begin{array}{lllll}\text { Bull., } & 14 & \text { (2) } & 92-96 & \text { (2010). }\end{array}$ doi:10.3329/cerb.v14i2.4910.

29) L. Zhao, and Z. Tang, "Investigate the cross - flow flat - plate photobioreactor for high - density culture of microalgae," (August) 1-11 (2018). doi:10.1002/apj.2247. 